J. Amer. Soc. Hort. Sci. 116(3):525-527. 1991.

\title{
Physiological Responses in Potato Plants under Continuous Irradiation
}

\author{
Weixing Cao and Theodore W. Tibbitts \\ Department of Horticulture, University of Wisconsin, Madison, WI 53706 \\ Additional index words. Solarium tuberosum, dry weight, leaf area, specific leaf weight, chlorophyll, photosynthesis, \\ carbohydrate
}

Abstract. The physiological responses of four potato (Solanum tuberosum $\mathbf{L}$.) cultivars to continuous irradiation were 'determined in a controlled environment. Under a constant $18 \mathrm{C}$ and a constant photoperiod of $470 \mu \mathrm{mol} \cdot \mathrm{s}^{-1} \cdot \mathrm{m}^{-2} \mathrm{of}$ photosynthetic photon flux, 'Denali' and 'Haig' grew well and produced large plant and tuber dry weights when harvested 56 days after transplanting. 'Kennebec' and 'Superior' were severely stunted, producing only $10 \%$ of the plant dry matter produced by 'Denali' and 'Haig'. The differences in leaf chlorophyll concentration and stomatal conductance were not consistent between these two groups of cultivars. The leaf net $\mathrm{CO}_{2}$ assimilation rates in 'Kennebec' and 'Superior' were lower, and intercellular $\mathrm{CO}_{2}$ partial pressures were higher than in 'Denali' and 'Haig'. These results indicate that inhibition of net $\mathrm{CO}_{2}$ assimilation in 'Kennebec' and 'Superior' was not due to a limiting amount of chlorophyll or to $\mathrm{CO}_{2}$ in the leaf tissues. Concentrations of starch in leaflets of 'Kennebec' and 'Superior' plants were only $10 \%$ of those in 'Denali' and 'Haig' plants, although soluble sugar concentrations were similar in the four cultivars. Therefore, the lower net $\mathrm{CO}_{2}$ assimilation rates in stunted 'Kennebec' and 'Superior' plants were not associated with an excess carbohydrate accumulation in the leaves.

Potatoes are grown under a wide range of locations throughout the world, ranging from $70^{\circ}$ latitude in northern Europe to the equator in the South American Andes mountains. In the northern-most latitudes, photoperiod during the growing season starts at $\approx 12 \mathrm{~h}$ at planting, increases to continuous light, and then decreases to $12 \mathrm{~h}$ at crop maturity. At the equator, the photoperiod is essentially constant at $12 \mathrm{~h}$. Although tuberization of some potato cultivars is delayed under long photoperiods, the plants still appear to grow normally (Chapman, 1958; Ewing and Wareing, 1978; Gregory, 1956; Haynes et al., 1988).

In our controlled-environment studies, cultivars such as 'Norland', 'Denali', 'Russet Burbank', and 'Haig' grew well under both continuous irradiation and 12-h photoperiod with constant temperature (Tibbitts et al., 1989; Wheeler and Tibbitts, 1986, 1987). However, other cultivars, such as 'Kennebec', 'Superior', and 'Norchip', exhibited distinct light injuries and stunting under long photoperiods,. particularly continuous irradiation (Tibbitts et al., 1989). No injury occurred in these cultivars under $12 \mathrm{~h}$ irradiation with constant temperature (Wheeler and Tibbitts, 1986). Alternating temperatures under continuous irradiation prevented light injury and allowed normal growth and tuberization on these plants (Tibbitts et al., 1990). It is possible that, under constant irradiation and temperature, the injured cultivars may not sustain continuous photosynthetic activity due to feedback" inhibition, possibly by high carbohydrate concentrations in the leaves. The feedback inhibition of photosynthesis by carbohydrate accumulation was shown by Foyer (1988) in the leaves of soybean (Glycine max) and spinach (Spinacia oleracea).

The present study was conducted to study the responses of photosynthesis and growth in potato cultivars grown with continuous irradiation. Specific analyses were undertaken to determine whether carbohydrate accumulation in leaves was high,

Received for publication 27 June 1990. Supported by the College of Agricultural and Life Sciences, Univ. of Wisconsin, Madison, and National Aeronautics and Space Administration grant NCC-2-301. The cost of publishing this paper was defrayed in part by the payment of page charges. Under postal regulations, this paper therefore must be hereby marked advertisement solely to indicate this fact. thus providing potential for feedback inhibition of $\mathrm{CO}_{2}$ assimilation in some cultivars.

\section{Materials and Methods}

Plant culture. 'Denali', 'Haig', 'Kennebec', and 'Superior' potatoes were grown in a controlled-environment room at the Biotron, Univ. of Wisconsin-Madison. 'Denali' and 'Haig' grow well under constant irradiation (long-photoperiod-tolerant), whereas 'Kennebec' and 'Superior' were severely stunted under constant irradiation (long-photoperiod-sensitive) (Tibbitts et al., 1989). Plants were raised from micropropagated stem cuttings grown in sterile agar culture (Hussey and Stacey, 1981). Uniform single plantlets were transplanted into 19-liter plastic pots containing a 1 peat : 1 vermiculite (v/v) medium and were grown for 56 days. The transplants were kept covered with glass beakers for the first 3 days to minimize transplant shock and to avoid desiccation. Fourteen days after transplanting, an additional $5 \mathrm{~cm}$ of medium was added to the pots to cover the lower plant nodes. Plants were watered to excess four times daily using a complete nutrient solution (Hammer et al., 1978).

The growth room was maintained at a daily average of 17.6 $\pm 0.4 \mathrm{C}$ and $71 \% \pm 6 \%$ relative humidity $(\mathrm{RH})$. Temperature and $\mathrm{RH}$ were monitored continuously by computer and checked daily using a thermocouple psychrometer. The irradiance level, provided by metal halide lamps and measured weekly with a LI-185 quantum meter (LI-COR, Lincoln, Neb.), was $470 \pm$ $24 \mu \mathrm{mol} \cdot \mathrm{s}^{-1} \cdot \mathrm{m}^{-2}$ of photosynthetic photon flux (PPF) (400$700 \mathrm{~nm}$ ) at the top of the canopy. Photoperiod was $24 \mathrm{~h}$ over the period of the whole experiment from transplanting. Carbon dioxide levels were ambient at $\approx 350 \mu \mathrm{l} \cdot$ liter $^{-1}$.

The experiment was a randomized complete block design with four cultivars and six replicates. The plants were blocked according to light level variation in the growth room. Each replicate for each cultivar was one plant in one container.

Gas exchange. Fifty days after transplanting, leaf $\mathrm{CO}_{2}$ assimilation and stomatal conductance were measured using a portable photosynthesis system with the $1 / 4-1$ iter LI-6000 leaf chamber (LI-COR). Measurements were taken on six replicate plants of each cultivar, with measurements made at two times separated by a 12-h interval (08:30 and 20:30 HR) and with three plants 
measured each time. At each time, three uniform shoots on each plant were selected for measurements. Measurements were taken on $9 \mathrm{~cm}^{2}$ of the terminal leaflet of the fourth leaf over $2 \mathrm{~cm}$ from the tip, which was almost fully expanded and well exposed.

Net $\mathrm{CO}_{2}$ assimilation rates and stomatal conductance for individual leaflets were determined from 10 sequential $\mathrm{CO}_{2}$ measurements at 4-sec intervals. The $\mathrm{CO}_{2}$ concentration was decreased to $\approx 20 \mu 1 \cdot$ liter $^{-1}$ below the ambient $350 \mu l \cdot$ liter $^{-1}$ during the measurement sequence of less than $1 \mathrm{~min}$.

During measurements, $\mathrm{CO}_{2}$ exhaled by workers was discharged from the growth room through face masks connected with tubing to vacuum pumps outside the room. Thus, $\mathrm{CO}_{2}$ concentrations within the room showed no change during the measurement period. The intercellular $\mathrm{CO}_{2}$ partial pressures in the leaves of the several cultivars were calculated using the equation given by Farquhar and Sharkey (1982).

Chlorophyll and carbohydrate assay. At 55 days after transplanting, the fourth leaf from the tip on three shoots from each plant was sampled for carbohydrate and chlorophyll analyses. The terminal leaflet was taken for chlorophyll extraction; the adjacent pair of opposite leaflets was used for carbohydrate analysis. Fresh weight and area of the leaflets were quickly recorded before placing them in $100 \%$ ethanol for total chlorophyll extraction (Knudson et al., 1977) or liquid $\mathrm{N}$ for carbohydrate analysis. Dry weights of the leaflets were taken after lyophilization for carbohydrate analysis. Dry matter content of these leaves was used to calculate dry weight of the terminal leaflets used for chlorophyll extraction. The leaf samples were taken separately for replicates 1 to 3 and replicates 4 to 6, with a 12-h interval between two times (08:30 and 20:30 HR).

For carbohydrate assay, lyophilized tissue was ground with mortar and pestle and extracted three times with $80 \%$ ethanol. The ethanol extracts were evaporated to dryness in vacuo. The residues were resuspended in warm water and filtered to obtain solutions for total soluble sugar analysis, which was run with an anthrone assay (Yemm and Willis, 1954). The pellets left after ethanol extraction were used for starch assay. Pellets were boiled for $1 \mathrm{~h}$ in $0.1 \mathrm{M}$ sodium acetate buffer, $\mathrm{pH} 4.5$, then incubated for $16 \mathrm{~h}$ at $45 \mathrm{C}$ with amyloglucosidase. The resulting glucose was assayed calorimetrically using glucose oxidase (Roper et al., 1988).

Plant harvest. At harvest, plants were separated into shoots, tubers, and roots, including stolons. Tissues were oven-dried at 70C for 2 days and dry weights determined. Dry weights of leaflets sampled for chlorophyll and carbohydrate analyses were added to the shoot dry weights obtained at harvest.

Data analysis. Analysis of variance showed that the measurements of gas exchange, chlorophyll concentrations, and carbohydrate concentrations taken $12 \mathrm{~h}$ apart were not significantly different, so the data from the three replicate plants at each time were grouped together for statistical analysis. Analysis of variance was performed on all data sets. Duncan's multiple range test was used for mean separation.

\section{Results and Discussion}

Plant growth. The long-photoperiod-tolerant 'Denali' and 'Haig' grew well, but the long-photoperiod-sensitive 'Kennebec' and 'Superior' were chlorotic and stunted within 14 days. The plants of 'Kennebec' and 'Superior' showed slight recovery before harvest. Dry weights of shoots, roots plus stolons, and tubers were much lower for 'Kennebec' and 'Superior' than for 'Denali' and 'Haig' (Table 1). 'Kennebec' and 'Superior' had
Table 1. Plant dry weight and leaflet characteristics in potato cultivars exposed to continuous irradiation.

\begin{tabular}{|c|c|c|c|c|c|c|c|c|}
\hline \multirow[b]{3}{*}{ Cultivar } & \multirow{2}{*}{\multicolumn{5}{|c|}{$\begin{array}{l}\text { Plant dry } w^{z} \\
(\mathrm{~g})\end{array}$}} & \multicolumn{3}{|c|}{ Leaflets ${ }^{y}$} \\
\hline & & & & & & \multirow{2}{*}{$\begin{array}{l}\text { Area } \\
\left(\mathrm{cm}^{2}\right)\end{array}$} & \multirow{2}{*}{$\begin{array}{c}\text { Dry wt } \\
\text { (mg) }\end{array}$} & \multirow{2}{*}{$\begin{array}{l}\text { Specific } \\
\text { leaf area } \\
\left(\mathrm{cm}^{2} \cdot \mathrm{g}^{-1}\right)\end{array}$} \\
\hline & Shoots & Roots & Tub & & Total & & & \\
\hline Denali & $170 a$ & $11.2 \mathrm{a}$ & 162 & $\mathrm{a}$ & $343 a$ & $11.6 \mathrm{a}$ & $76.0 \mathrm{~b}$ & $154 \mathrm{c}$ \\
\hline Haig & $117 b$ & $4.2 \mathrm{~b}$ & 155 & a & $276 \mathrm{~b}$ & $12.7 \mathrm{a}$ & $96.7 \mathrm{a}$ & $134 \mathrm{~d}$ \\
\hline Kennebec & $27 c$ & $0.7 c$ & & & $28 \mathrm{c}$ & $8.0 c$ & $46.1 \mathrm{c}$ & $176 \mathrm{~b}$ \\
\hline Superior & $31 \mathrm{c}$ & $0.8 \mathrm{c}$ & & & $33 c$ & $9.8 \mathrm{~b}$ & $43.7 c$ & $226 \mathrm{a}$ \\
\hline
\end{tabular}

${ }^{2}$ Means of six replicate plants. Mean separation in columns by Duncan's multiple range test, $P=0.05$.

${ }^{y}$ Data for terminal and adjacent paired leaflets of the leaves used for chlorophyll and carbohydrate analyses. Averages of leaf samples from each of six replicate plants.

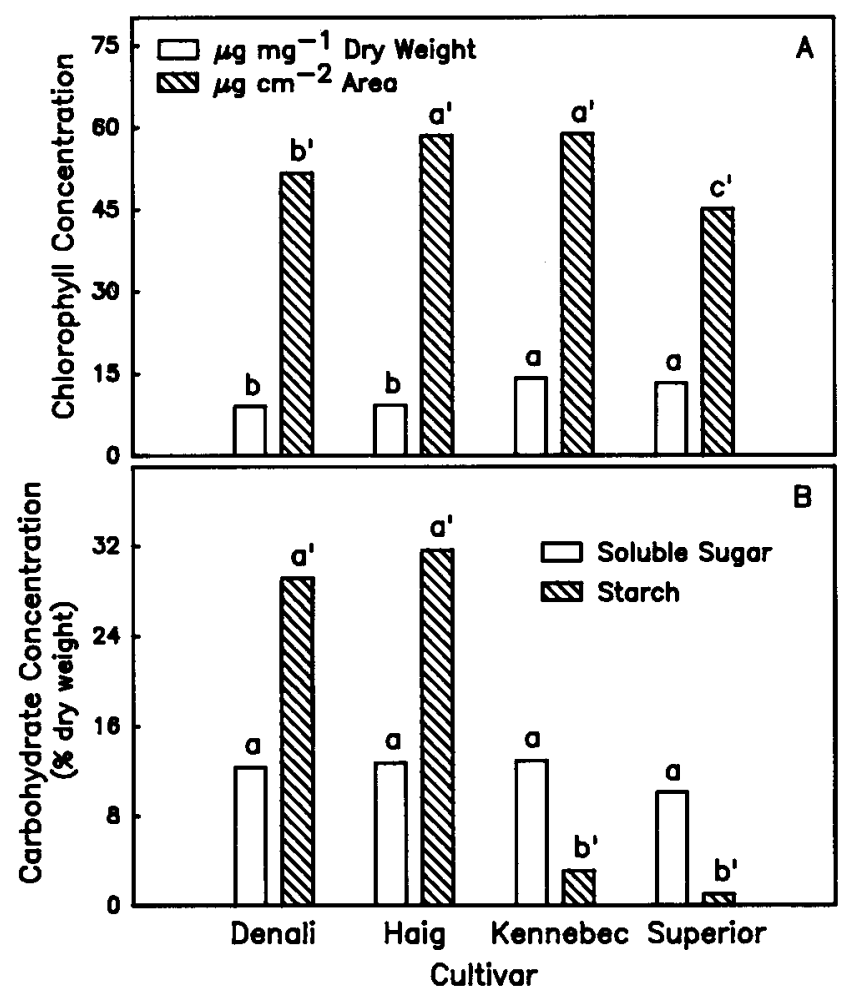

Fig. 1. The concentration of chlorophyll (A) and starch and total soluble sugars (B) in the leaflets of potato cultivars grown under continuous irradiation. Values are means of six replicate plants. Mean separation in each data set by Duncan's multiple range test, $P=$ 0.05 .

only a few small tubers, weighing $<1 \mathrm{~g}$ dry weight/plant, while 'Denali' and 'Haig' produced $>150 \mathrm{~g} /$ plant. These differences between the cultivars are consistent with previous observations (Tibbitts et al., 1989; Wheeler and Tibbitts, 1986).

'Denali' produced $\approx 50 \%$ more shoot and root plus stolon dry weights than 'Haig', but similar tuber dry weight (Table 1). The harvest index was 0.47 for 'Denali', but 0.56 for 'Haig'. Thus, 'Denali' developed more vegetative growth than 'Haig'. Shoots were responsible for $>95 \%$ of the total dry weight of 'Kennebec' and 'Superior'.

'Kennebec' and 'Superior' produced smaller (27\%) leaflets but higher $(40 \%)$ specific leaf area (SLA, $\left.\mathrm{cm}^{2} \cdot \mathrm{g}^{-1}\right)$ than 'Denali' or 'Haig' (Table 1). This difference in SLA suggests that there was significantly less dry matter accumulation per unit 


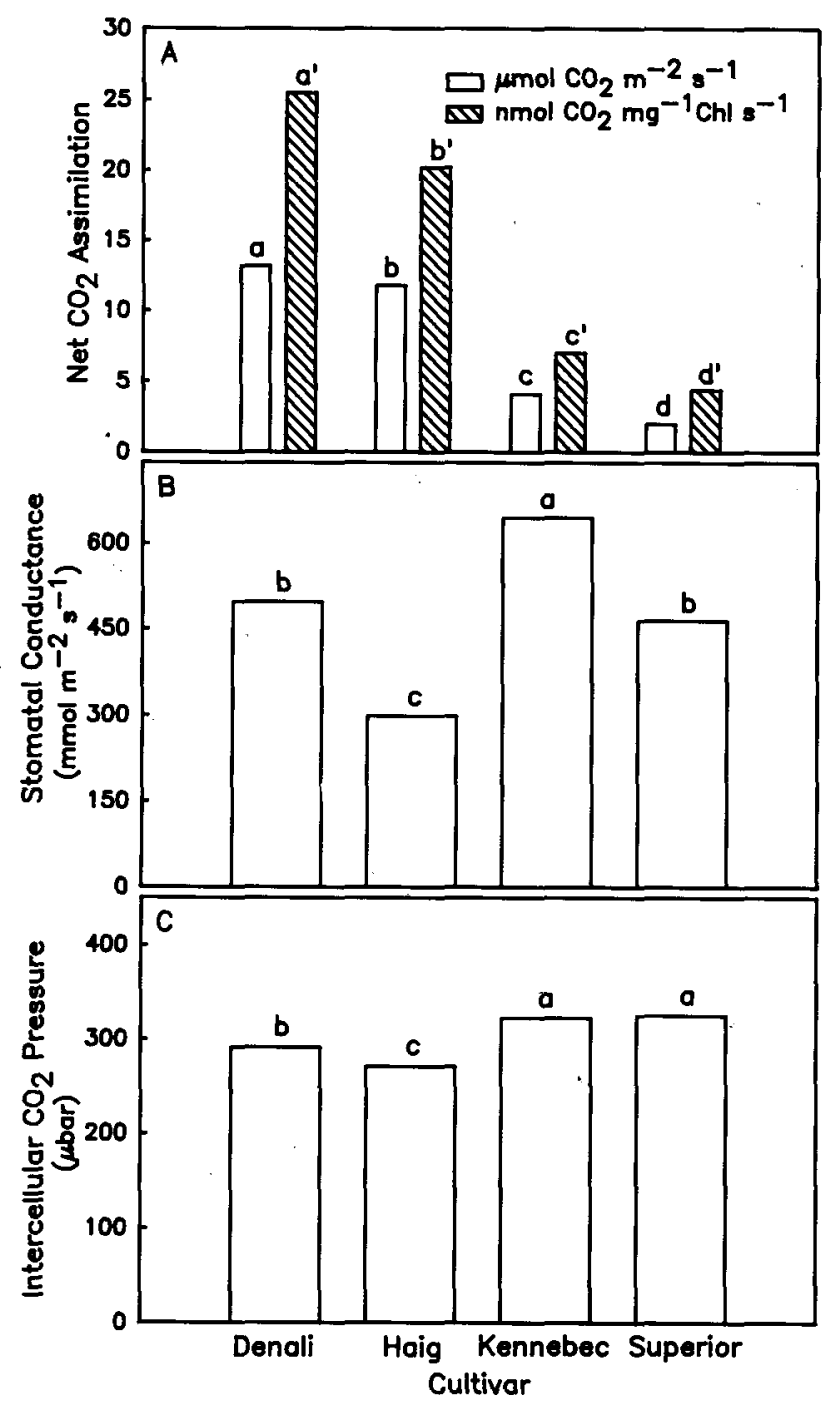

Fig. 2. Net $\mathrm{CO}_{2}$ assimilation (A), stomatal conductance (B), and intercellular $\mathrm{CO}_{2}$ partial pressure $(\mathbf{C})$ in the leaflets of potato cultivars grown under continuous irradiation. Values are means of six replicate plants. Mean separation in each data set by Duncan's multiple range test, $P=0.05$.

leaf area in 'Kennebec' and 'Superior' than in 'Denali' and 'Haig'.

Chlorophyll concentration. In leaflets of 'Kennebec' and 'Superior', chlorophyll concentrations on a dry-weight basis were greater than in those from'Denali' and 'Haig' (Fig. 1A). In contrast, chlorophyll concentrations on a leaf-area basis did not differ consistently between these four cultivars. The higher chlorophyll concentration per leaf dry weight for 'Kennebec' and 'Superior' apparently resulted from the higher SLA for these two cultivars.

$\mathrm{CO}_{2}$ assimilation. Net $\mathrm{CO}_{2}$ assimilation rates per unit leaf area in 'Kennebec' and 'Superior' were $\approx 30 \%$ of rates in 'Denali' and 'Haig' (Fig. 2A). The pattern among cultivars was similar for $\mathrm{CO}_{2}$ assimilation expressed on the basis of leaf chlorophyll concentration (Fig. 2A).

Leaf stomatal conductance did not differ consistently between the four cultivars (Fig. 2B). It was highest for 'Kennebec', lowest for 'Haig', and intermediate for 'Denali' and 'Superior'. 'Kennebec' and 'Superior' maintained high stomatal conductance, while net $\mathrm{CO}_{2}$ assimilation was very low in the leaves.
As a result, the intercellular $\mathrm{CO}_{2}$ partial pressure in the leaves was significantly higher in the two sensitive cultivars than in the two tolerant cultivars (Fig. 2C). The results indicate that photosynthetic inhibition in 'Kennebec' and 'Superior' under continuous irradiation was not due to a limiting amount of $\mathrm{CO}_{2}$. Therefore, the reduced $\mathrm{CO}_{2}$ assimilation in these cultivars apparently resulted from reduced photosynthetic activity within the leaf tissues. A similar observation was reported by Wolf et al. (1990) with high-temperature effect on photosynthesis in potatoes.

Carbohydrate concentration. Starch concentrations in leaflets of 'Kennebec' and 'Superior' were only $10 \%$ of those for 'Denali' and 'Haig' (Fig. 1B). However, total soluble sugar concentrations were similar for all four cultivars. The high starch concentrations in leaves of 'Denali' and 'Haig', in excess of $25 \%$ of the dry weight, were apparently related to high photosynthetic activity under continuous irradiation. With $\mathrm{CO}_{2}$ enrichment studies, a similar high level of starch accumulation was observed in potato leaves (data not shown). Starch concentrations of tomato leaves increased significantly under elevated $\mathrm{CO}_{2}$ concentrations (Madsen, 1968).

In conclusion, plant dry weights, $\mathrm{CO}_{2}$ assimilation rates, and leaf starch concentrations under continuous irradiation were significantly lower in the long-photoperiod-sensitive cultivars Kennebec and Superior than in the tolerant cultivars Denali and Haig. The results demonstrate that the lower $\mathrm{CO}_{2}$ assimilation rates and stunted growth in 'Kennebec' and 'Superior' were not associated with an excess carbohydrate accumulation in the leaves; thus, feedback inhibition from starch accumulation apparently was not a cause of the injury in these cultivars.

\section{Literature Cited}

Chapman, H.W. 1958. Tuberization in the potato plant. Physiol. Plant 11:215-224.

Ewing, E.E. and P.F. Wareing. 1978. Shoot, stolon, and tuber formation on potato (Solanum tuberosum L.) cuttings in response to photoperiod. Plant Physiol. 612:348353.

Farquhar, G.D. and T.D. Sharkey. 1982. Stomatal conductance and photosynthesis. Annu. Rev. Plant Physiol. 33:317-345.

Foyer, C.H. 1988. Feedback inhibition of photosynthesis through source-sink regulation in leaves. Plant Physiol. Biochem. 26:483-492.

Gregory, L.E. 1956. Some factors for tuberization in the potato plant. Amer. J. Bet. 43:281-288

Hammer, P. A., T.W. Tibbitts, R.W. Langhans, and J.C. McFarlane. 1978. Baseline growth studies of 'Grand Rapids' lettuce in controlled environments. J. Amer. Soc. Hort. Sci. 103:649-655.

Haynes, K. G., F.L. Haynes, and W.H. Swallow. 1988. Temperature and photoperiod effect on tuber production and specific gravity in diploid potatoes. HortScience 23:562-565.

Hussey, G. and N.J. Stacey. 1981. In vitro propagation of potato (Solanum tuberosum L.). Ann. Bet. 48:787-796.

Knudson, L. L., T.W. Tibbitts, and G.E. Edwarda. 1977. Measurement of ozone injury by determination of leaf chlorophyll concentration. Plant Physiol. 60:601608.

Madsen, E. 1968. Effect of CO-concentration on the accumulation of starch and sugar in tomato leaves. Physiol. Plant. 21:168-175.

Roper, T. R., J.D. Keller, W.H. Loescher, and C.R. Rem. 1988. Photosynthesis and carbohydrate partitioning in sweet cherry: Fruiting effects. Physiol. Plant 72:4247.

Tlbbitts, T. W., S.W. Bennett, and W. Cao. 1990. Control of continuous irradiation injury on potatoes with daily temperature cycling. Plant Physiol. 93:409-411.

Tibbitts, T. W., S.M. Bennett, R.C. Morrow, and R.J. Bula. 1989. Utilization of white potatoes in CELSS. Adv. Space Res. 9:853-859.

Wheeler, R.M. and T.W. Tibbitts. 1986. Growth and tuberization of potatdSolanum tuberosum L.) under continuous light. Plant Physiol. 80:801-804.

Wheeler, R.M. and T.W. Tlbbitts. 1987. Utilization of potatoes for life support systems in space 111. Productivity at successive harvest dates under 12-h and 24h photoperiods. Amer. Potato J. 64:311-320.

Wolf, S., A.A. Olesinski, J. Rudich, and A. Marani. 1990. Effect of high temperature on photosynthesis in potatoes. Ann. Bet. 65:179-185.

Yemm, E.W. and A.J. Willis. 1954. The estimation of carbohydrates in plant extracts by anthrone. Biochem. J. 57:508-514. 